\title{
Relationship Between Artificial Intelligence and the Engagement Variable
}

\author{
García-Navarro C,* Pérez Lozano C, Cardoso-Botelho M, Reyes Martínez RM, Martínez Agenjo A \\ Erudit AI Inc., US
}

\begin{abstract}
The purpose of this research is to learn how engagement has been measured so far and what new techniques will be used to measure it in the future. To this end, firstly, there is a review of all the current research in engagement has been conducted, in addition to a review of the current traditional techniques used to measure it. Secondly, the concept of Artificial Intelligence has been analyzed and how one of its most common techniques (Natural Language Processing) is starting to be used as a new technique to measure engagement. Once the traditional and new techniques had been presented, a theoretical differentiation was made between them in order to test the benefits of the latter. The main conclusions were that Artificial Intelligence is increasing its fields of action, specifically in the psychology of organizations. In this field, the new techniques allow companies to save time in the administration and the conduction of surveys. Moreover, the data reported by AI is less biased than the one that comes from surveys, since the data is collected directly and these techniques do not bias the employee when answering the items. As a final conclusion, it is proposed that a study be carried out to compare the results of both techniques in real-life companies.
\end{abstract}

Keywords: Artificial intelligence, Engagement, NLP, Companies, Neural networks

\section{Objective}

The main objective of the research has been to present new techniques to measure the engagement variable within the psychology of organizations and to expose which are the main benefits compared to traditional techniques.

\section{Introduction}

\section{Engagement's framework}

Engagement has been defined as an attitude towards work. It is a state in which an employee identifies with a particular organization and its goals, and wishes to remain in it as one of its members. This denotes personal commitment, and an overall psychological state of well-being towards the company. Authors Romero Espínola and Palacini ${ }^{1}$ describe engagement as a positive, satisfying and work-related state of mind, characterized by vigor, dedication and absorption. Similarly, Bakker and Demerouti ${ }^{2}$ indicate that engaged employees are energetic (vigor), enthusiastic about their work (dedication) and can be fully immersed in their work duties, such that they lose track of time (absorption).

One of the most commonly applied engagement models is the Job Demands-Resource (JD-R) model. According to it, there are 2 types of resources: work and personal resources. The former refers to the physical, social or organizational work elements which can reduce work demands, and psychological and physiological costs. Consequently, there is an improvement of goal accomplishments while stimulating personal growth, education and development. The second resources are positive resilience self-assessments, which refer to individuals' ability to manage and impact their work environment. Bakker and Demerouti ${ }^{2}$ carried out research on this model confirming that job resources such as autonomy, social sup-

\begin{tabular}{|l|l|}
\hline \hline Quick Response Code: & *Corresponding author: Claudia García-Navarro, Erudit AI Inc., 92 SW 3RD ST, 3310 Miami, \\
FL, Estados Unidos, US & Published: 24 August, 2021 \\
Received: 04 August, 2021 \\
Citation: García-Navarro C, Pérez Lozano C, Cardoso-Botelho M, Reyes Martínez RM, Martínez \\
Agenjo A. Relationship Between Artificial Intelligence and the Engagement Variable. J Psych Sci \\
Res. 2021;1(3):1-4. DOI: 10.53902/JPSSR.2021.01.000515
\end{tabular}


port and learning opportunities are strong drivers of engagement. In addition, personal resources were also identified as engagement predictors. $^{3}$

Research by Reis, Hoppe, and Schroder ${ }^{4}$ suggests that the JD-R model shows that engagement leads to positive organizational outcomes. Among these are positive performance, organizational commitment and lower turnover. Recently, low engagement has also been considered as a mental health predictor to depressive symptomatology, ${ }^{5}$ sleep problems, ${ }^{6}$ and global mental health. ${ }^{7}$

\section{Advantages of high levels of engagement for companies}

Within the potential engagement consequences are positive approaches to well-being, global health, and to job performance. Moreover, highly engaged employees are more committed to the organization, are less absent and have no intention of leaving the company compared to those who do not feel engaged. They show advantages of positive emotions of sane mental and psychosomatic health. Fewer errors are reported and they are less frequently involved in workplace injuries and accidents. They present innovative work tendencies and are more likely to have higher effectiveness and performance rates. In addition, personal initiative and strong motivation to learn is frequent among engaged workers. This suggests that committed workers are both capable and willing to make an extra effort. ${ }^{8}$ A meta-analysis involving nearly 8,000 business units from 36 companies $^{9}$ propose that engagement levels are positively correlated with business performance (i.e., customer satisfaction and loyalty, profitability, productivity, turnover, and safety). Taken together, these findings suggest that engagement provides a significant advantage to organizations, lowering turnover and human resource costs, and incrementing productivity. ${ }^{10}$

\section{Impact of engagement for companies}

As a way for companies to avoid the costs derived from turnover, strategies must be implemented to retain personnel who bring significant value to the company and who exert a great impact on the culture, process and economics of the organization. ${ }^{11}$ Moreover, identifying low engagement predictors allows prevention to keep such problems from reaching higher levels. For example, 2 low engagement behaviors that can appear before quitting are the desire to leave and the intention to retire. One of the strategies consists in identifying the reasons for turnover, when and why it starts. Therefore, showing the engagement levels of the company's employees will help to identify those with low levels, and prevention strategies can be employed so that they do not end up rotating, maintaining the company's productivity and reducing costs.

\section{Traditional evaluation of engagement}

The most widely used instrument to measure engagement is the Utrecht Work Engagement Scale. ${ }^{12}$ It has been validated worldwide and shows favorable psychometric properties. The scale has
3 major dimensions. The first-dimension concerns vigor, which refers to the person's willingness to devote effort and persistence to work when facing problems. The second, concerns dedication, which refers to commitment to work, feeling of excitement, inspiration, pride and feeling challenged. The third dimension, absorption, refers to concentration and being completely immersed in work, so that time perception is distortionated and there is a feeling of displeasure when leaving work. ${ }^{13}$

Nevertheless, Artificial Intelligence (AI) techniques are a recent incorporation to this research field. Specifically, Natural Language Processing (NLP) is being applied to detect companies' engagement levels. Although, in order to understand how it is being applied, it first requires knowledge on NLP.

\section{Relationship between AI and NLP}

\section{Natural Language Processing}

The concept of NLP has been exponentially evolutionized from 1970 to recent years given the large volume of available data. Language consists of a generally infinite set of sentences that are formed by word-combinations that follow semantic and syntactic norms. Language is the action that expresses thoughts and communication between people. It is provided by vocal sound signals (voice) and/or by written signals (text). Distinctions can be made between Natural Language (NL; English, German, Spanish, etc.) and Formal Language (FL; mathematical, logical, etc.).

\section{Natural Language}

Refers to the everyday means to communicate with other people. It has been developed and organized from human experience, being used to analyze complex situations and reason about them in delicate ways. The semantic components that reinforce NL add to its expressive power and add value as a reasoning tool. Hence, the syntax of NL can be easily modeled with the other type of language; FL.

\section{Formal Language}

Refers to the type of language that humans have developed to express specific situations in each area of scientific knowledge. The words and sentences of FL are concretely defined (words maintain the same meaning regardless of the context). This type of language is free of any semantic component outside of its operators and relations. They can be implemented free of ambiguity to structure sciences such as mechanics, physics, mathematics, electrical engineering. Within FL, Programming Language is defined as a set of elements organized by grammatical rules that allow us to write in a technological program. This type of language has 2 essential elements: syntax and semantics. Syntax is the correct order of the lexical components, that is, the set of rules that define the combination of symbols that are considered correctly structured elements 
or expressions. Semantics ensure that each sequence used has a correct meaning.

Hence, one of the fundamental tasks of $\mathrm{AI}$ is the manipulation of NL through computational tools. By joining the programming language and NL, we get NLP, which can understand, interpret and manipulate human language. NLP use cases are primarily based on the application of $\mathrm{AI}$ and embedded Machine Learning. ${ }^{14}$

\section{Artificial Intelligence}

Recents studies by Hirschberg and Manning ${ }^{15}$ point out that AI helps to better understand language through high-performance tools and methods. Through data, these new methods allow the realization of discourse analysis identifying the syntax, semantic information and context.

Although language can be perceived as non-qualitative, specialized measuring techniques for communication have been developed. Earlier communication originated in the world of social sciences, where qualitative measurement techniques were normally applied, similar to words and the descriptive. In contrast, the opposite occurs with numbers, which can be measured quantitatively. ${ }^{16}$

As Steckler, et al. ${ }^{17}$ already stated, this differentiation has already been made. That is that when selecting the techniques with which to work, researchers have been splitted in quantitative and qualitative, assigning to their investigations one or another depending on the field of work. However, specifically in the field of social sciences applied to health, this has triggered a great debate, since researchers in these areas consider that their research cannot be framed solely in qualitative research, mainly due to its lack of validity.

In psychology to evaluate language, as of today only qualitative techniques have been used. However, if we only apply the qualitative analysis method without algorithmic learning, nuances of text can escape us, this is known as data-driven. ${ }^{18}$ To solve this problem, $\mathrm{AI}$ is used, since it learns, automates and links neighboring words semantically in a different way in order to have a communication context.

Convolutional Neural Networks (CNN) are responsible for this, analyzing the words contained in the text, adding one value or another depending on the other words that are accompanied by. So that it can be understood, here is an example: in a sentence such as "I really want to face this new project, without a doubt I will do my best" the AI can detect a $90 \%$ level of engagement for the words it contains. However, if in the sentence we say "This new project is taking away my desire to work" the level will be $30 \%$. In this case, the words new and project are two words with a high load of meaning, therefore, the CNN will not evaluate them in the same way if they are accompanied by "facing" as if they are accompanied by "removing". The network will identify in the first case that the person is happy and will assign an engagement level of 90, however, if they are accompanied by taking away the desire, it will assign a 30 because the information about the person is negative.

Based on scientific evidence that studies don studies that claim that AI can be used beneficially in the field of mental health through NLP. ${ }^{19}$ Semantic analysis is used for the interpretation, comprehension and manipulation of human language, to automate and train AI to prevent mental health problems in employees of different companies.

\section{Conclusion}

Artificial Intelligence is growing its presence in the field of organizational psychology in order to know the level of employee engagement. The new engagement detection techniques will allow companies to save time in administration management and dealing with the corrections of the random surveys. The data reported by these new techniques will be less biased than traditional survey data, because through semantic analysis the tool will be able to check the level of employee engagement without the need for the employee to answer surveys. It would be of great interest to do a study comparing the results generated by a traditional technique as surveys and a new technique as an AI tool.

\section{Acknowledgments}

None.

\section{Funding}

None.

\section{Conflicts of Interest}

Author declares that there is no conflict of interest.

\section{References}

1. Romero Espínola RR, Palacini F. Relationship between engagement levels and rotation intention levels in employees of two private companies in Asunción. Revista Científica de la UCSA. 2020;7(2):3-25.

2. Bakker AB, Demerouti E. Towards a model of work engagement. Career development international. 2008;13(3):209-223.

3. Sweetman D, Luthans F. The power of positive psychology: Psychological capital and work engagement. Work engagement: A handbook of essential theory and research. 2010. pp. 54, 68.

4. Reis D, Hoppe A, Schröder A. Reciprocal relationships between resources, work and study engagement, and mental health: Evidence for gain cycles. European Journal of Work and Organizational Psychology. 2015;24(1):59-75.

5. Hakanen JJ, Schaufeli WB. Do burnout and work engagement predict depressive symptoms and life satisfaction? A three-wave seven-year prospective study. J Affect Disord. 2012;141(2-3):415-424.

6. Kubota K, Shimazu A, Kawakami N, et al. The empirical distinctiveness of work engagement and workaholism among hospital nurses in Japan: The effect on sleep quality and job performance. Ciencia \& Trabajo. 2011;13(41):152-157.

7. Demerouti E, Mostert K, Bakker AB. Burnout and work engagement: 
a thorough investigation of the independency of both constructs. J Occup Health Psychol. 2010;15(3):209-222.

8. Bakker AB, Schaufeli WB. Positive organizational behavior: engaged employees in flourishing organizations. Journal of Organizational Behavior. 2008;29(2):147-154.

9. Harter JK, Schmidt FL, Hayes TL. Business-unit-level relationship between employee satisfaction, employee engagement, and business outcomes: a meta-analysis. J Appl Psychol. 2002;87(2):268-279.

10. Robbins SP, Judge TA. Los equipos de trabajo. Comportamiento Organizacional México DF, México: Pearson Education. 2009.

11. Alvarado MC, Castro HC, Sánchez RE. Relación entre la satisfacción laboral y el engagement en la intención de rotar en una empresa minera. 2017.

12. Schaufeli WB, Bakker AB. Defining and measuring work engagement: Bringing clarity to the concept. Work engagement: A handbook of essential theory and research. 2010; pp. 10-24.

13. Laureano Anquipa SE, Ortiz Soriano DE, Valle Herrera LM. Validación de la Utrecht Work Engagement Scale (UWES) en personal docente de pre-grado de universidades privadas en Lima Metropolitana. 2020.

14. Hirschberg J, Manning CD. Advances in natural language processing. Science. 2015;349(6245):261-266.

15. Taylor SJ, Bogdan R. Introducción a los métodos cualitativos de investigación (Vol.1). Barcelona: Paidós. 1987.

16. Steckler A, McLeroy KR, Goodman RM, et al. Toward integrating qualitative and quantitative methods: An introduction. Health Education Quarterly. 1992;19(1):1-8.

17. Rodriguez M, Sivic J, Laptev I, et al. Data-driven crowd analysis in videos. In 2011 International Conference on Computer Vision. IEEE. 2011; pp. 1235-1242.

18. Sancho Escrivá JV, Fanjul Peyró C, de la Iglesia Vayá M, et al. Aplicación de la inteligencia artificial con procesamiento del lenguaje natural para textos de investigación cualitativa en la relación médico-paciente con enfermedad mental mediante el uso de tecnologías móviles. Revista de Comunicación y Salud. 2020;10(1):19-41. 